Chapter 24

\title{
Interactive and Multimedia Atlas Information Systems as a Cartographic Geo-Communication Platform
}

\author{
Mirjanka Lechthaler \\ Department of Geoinformation und Cartography, Vienna University of \\ Technology, Austria \\ lechthaler@tuwien.ac.at
}

\begin{abstract}
In modern cartography of the late twentieth century the Internet offers an ideal platform for making communication with maps more feasible - on one hand. But on the other hand there has to be an understanding of the process and the methods of how to generate cartographic models and then how to communicate spatial data, which means geo-information accurately and efficiently. Due to this focus, cartography has to fulfil the obligation to achieve both - the creation of cartographic presentation forms for the new media and to accept the responsibility on understanding the deep relations within the whole cartographic communication process, which includes the user, the models in different cartographic media and the transmission.

In this article, the importance of interactive and multimedia atlas information system as cartographic geo-communication platforms will be presented, where the user expands his knowledge by restrictive but flexible searching for spatial information. An atlas information system subdivides all functionalities into a cartographically conceptional and structured order.
\end{abstract}

\subsection{Introduction}

Cartography is an indispensable part of any future for geography and the broader enterprise for geographic information science (Goodchild 2000). The digital map world and the daily increasing number of maps lead to the known paradox between 
marginalization of cartography and the increasing need for good map products included in cartographic information and communication systems (CICS), based predominantly on visual communication.

Over the last 20 years, the Internet has been a new information transfer medium for cartography and cartographic applications. It offers a variety of ways to communicate geo-information via adequate geo-visualisation of basic geo-data (topographic and thematic).

The communication of geo-information facilitated by CICS is based on maps as user interfaces, which are not only restricted to the visual recognition patterns. The individual user's interest could be satisfied with CICS geo-information only if there is a different content depth and a different scale level - level of details. By means of offered and applied interactive tools the acquisition of spatial information is in principle not static. The user defines, depending on his aims, his own personal form of communication.

The important cartographic web media are regional, national and global atlases in the form of web-based, multimedia and interactive atlas information systems (MI-AIS). There is the need of cartographic principles, good design and skills stronger than ever, with the aim to make the communication of spatial information richer, more efficient, personalized and ubiquitous.

In the next chapter the author will make a short walk through the history of coping with "cartographic communication" and will give the ability to understand the changes over the years caused by new technology.

\subsection{Concepts Worth Knowing for Understanding Cartographic Communication}

The following map functionalities in a CICS are the author's selection with the aim to give a representative review, which is standing for all characteristics of this process. The pregnant description of each of them will give the possibility to see of what prime importance the maps were and still are in our private and public realm.

\subsubsection{Predictions of Cartographic Communication}

Information theory and several attempts made at practical application of SHANNON's formulae in determining information capacity of maps (Sukhov 1967, Knöpfli 1980, Lechthaler 1985) as a carrier of geo information influenced the formulation of a "new" approach to the role and tasks of cartography and it set the background for a trend then called "cartographic communication". The model 
of cartographic communication in the late sixties of the twentieth century inspired further research and discussion till today.

Bocharov (1966) was the first who defined cartography as a science concerning a cartographic form of information transmission.

Kolačny's (1970) main work for cartography was presented in his article "Kartographische Informationen - ein Grundbegriff und Grundterminus der modernen Kartographie" (Kolačny 1970, p. 188). After studying the complex problems of "modern" cartography, he came to the conclusion that cartography can only be understood and the communication problems can only be solved, if the cartographers consider that the creation and utilization of cartographic products are two components of an interrelated process in a "stimulus-response" model. The author called it "communication of cartographic information", where the central element is "cartographic information". His idea has the following fundamental points in the so called communication circle:

- Anticipated monitoring of multi-dimensional universe/reality by the cartographer, with specific objectives in mind,

- Development of a cognitive concept of anticipated reality,

- Mental transformation of this concept into cartographic information,

- Objectification/formalization of cartographic information/map which stands for the reality,

- Effect of objectification of cartographic information in the process of map reading,

- Effect of understanding cartographic information, creation of user's cognitive model of reality and

- Pragmatic behaviour of map user in his world/reality.

In "The science of cartography and its essential processes", Morisson (1976 , p. 86) presents the vision of cartography as a scientific study of the map as a communication channel. There are many essential processes; on one side there are the cartographer's cognitive selections of geo-space data, his data classification and data simplification to form his map conception and map construction though cartographical methods of generalisation and visualisation. On the other side there are the reader's cognitive interpretation and verification of received information in the cartographic communication process. It will only be successful, if the map reader's abilities were taken into account.

The model of cartographical transmission after Ratajski (1978, see also Morrison 1976, p. 75) deals with the map as a model of reality, which is conditioned by two elements: structure (i.e. construction of cartographic expression) and content, which have to be transmitted. So, the map has a transmission capacity where the cartographic language (well established syntactical structure and grammar) has a strong influence. 
Board (1978, p. 42) suggests a few ways in which a conceptual model of cartographic communication could be functional. His model is based on cognitive maps included in different relationships between four corners in his communication circle: real world, map maker, physical map and map reader. In order to make maps more efficient, the author develops the theories of cartographic communication.

Grygorenko (1984 , p. 102) explains the map position in the system of cartographic communication through a general theory of (cybernetic) systems with four partial processes: gaining knowledge of reality, producing the cartographic message, interpreting the message and verification of the message. The cognitive map of reality has a central relevance as well as the possibility of representing it by a material model. Without the representation function the cartographic message would have no sense and would never have a practical importance.

\subsubsection{Cornerstones of Modern Cartographic Communication}

In all mentioned schemes of cartographic communication, independently of terminological differences, the same unchanged arrangement was always preserved: reality $\rightarrow$ map maker $\rightarrow$ map $\rightarrow$ map user $\rightarrow$ mental image of reality $\rightarrow$ user's behaviour. This model is typical for any communication system. The information flow through the substantial system channel reaches the recipient more or less correct. In cartographic communication the map i.e. cartographic information is a central element that carries spatial information. This entails, irrespective of the technology of the communication system, various semiotic, modelling and cognitive implications.

MacEachren (1995, p. 5) sees the primary function of cartography as a formal communication system and the maps i.e. cartographic signatures, as a vehicle for transferring spatial information. This cybernetic process (Grygorenko 1984, Taylor 1994) has inputs, transmissions, receptions of information and therefore allows to be analysed as a system in its functionality. The aim is to transport the space simplified, generalised, classified and symbolized without filtering or less information and to expand the user's knowledge.

DiBiase's characterisation of cartographic visualisation matches the view that the interpretation of spatial phenomena depends on visualisation by means of maps (see in: MacEachren 1994, p. 3). Giving a framework for thinking in spatial scientific research, he emphasises the role of all aspects of maps, from initial data exploration in private realm to the final presentation of results in public realm for visual communication. Maps are research and reasoning tools.

After the "stimulus-response" model, Peterson $(1995$, p. 6) the model includes interactions in the use of maps. The interactive communication is under user control. The interactive mapping environment (provided by the cartographer) allows the user to match the map according to his tasks, needs and abilities. In the author's 
opinion it is evident that the human mind is well-trained to recognise reality from animated presentations.

MacEachren (1995, p. 358) and Kraak et al. (1996, p. 3) depict cartography as a cubic map-use space in which visualisation and communication stand in opposite corners. For MacEachren the main aim is to make sense of how scientific visualisation links with cartography and not with map making. His space is defined by three map use axes:

- Private (private generating of maps for own needs) - public (access to previously prepared maps)

- Revealing unknowns (looking for something interesting) - presenting knowns (attempting to access particular geo-information)

- High human map interaction (manipulating maps in essential way: changing views, switching among different maps, superimposing map content, merging maps) - low interaction (limited ability to change the presentation).

For Kraak et al. $(1996$, pp. 41, 49) the starting points of the cartographic communication process are the data/information collected on the part of any third parties. Cartographers have to study and get acquainted with it, as well as with the purposes of the information transfer, applying the necessary data transformation with the aim of their correct presentation in a map format. The cartographic presentation is a cognitive process, which has to get the essence of spatial phenomenon, if it is represented adequately. The authors get maps by a form of scientific visualisation. The objective of cartography from their point of view is to convey spatial information and their spatial relationships, the aims of communication, exploration and analysis.

Cartwright et al. (1999, p. 8) include the concept of interactive multimedia and hypermedia in the cartographic communication process. Multimedia cartography can be presented as sphere of cartographic potential, which moves across and into a space of geographical reality (composed of abstraction-level), allowing the user, depending on his point of contact (POC), to control and to choose the process of presentation according to his needs, abilities and skills. POC is like the geographical window through which reality can be seen. The authors compare multimedia cartography with the metaphor of an atlas information system.

Lechthaler $(2000,2002,2003,2005 \mathrm{a})$ has addressed the paradox between the marginalization of cartography and the increasing daily need for efficient cartographic information to be included in CICS. This interest focused on the current major problem related to the value of cartographic information as well as their restrictions, especially in the web environment, and how to deal with geo-communication assisted by maps, especially in MI-AIS.

Nowadays, in many cases the experienced cartographer is not the actual designer of the CICS. The user is invited to form and structure knowledge using the CICS on the web, where he is restricted by the limitations of current hardware, transforma- 
tion and visualisation tools or the high associated acquisition costs of such. Internet services and newly implemented information and telecommunication technologies allowed a new concept of improvement in geo-communication and support the user's arrangement and designing of geo-space as well as multimedia and interactive exploration of spatial information.

In Figure 24.1 the characteristics of cartographic information and the changed cartographic geo-communication process are presented respectively. The cartographer, being conscious of the scale and graphic design restrictions in the modelling process of the map space in the MI-AIS, constructs a content level based on different scale retaining and providing the analogies to the geo-space and links the resultant cartographic information with interactive and multi-/hypermedia information environments for display and use in a CICS. In this case the user is directly involved in the interactive geo-communication process that enables restrictivity as well as flexibility in individual and dynamic acquisition and/or generation of spatial information in the MI-AIS.

\subsubsection{Cybercartographic Geo-Communication}

Furthermore, we live in a new era of cartography - a cybercartography where cartography has developed its own theoretical language frameworks and the communication takes place using more resources including cartographic, linguistic, mathematical, statistical, musical, and visual languages. Maps, virtual space maps, dynamic three-dimensional satellite images, geo-text, videos, photos, sound, computer simulations, statistical graphs, and diagrams can be used in the construction of so called cybercartographic MI-AIS. In this case, the centre of cartographic activity does not lie in the production and use of printed maps as the primary and final product. Geo-communication, using cybercartographic atlases, proceeds in the multi-dimensional space and is composed of three axes: communication, models, and knowledge. In many cases the incorporated AIS, information and knowledge about human geography, landscape ecology, territorial planning, environmental science, and other relevant sources will be provided by a number of authors/users. There is an active cycle of scientific research that involves empirical work, creation of knowledge, and feedback between users and atlas developers, including experts, scientists, students, fieldworkers, and governmental officials. The cybercartographic MI-AIS execute their full cybernetic character through the interaction between all actors in the group-communication process, the role which is to facilitate human communication. Users and atlas get engaged in a process of conversation and knowledge construction within using the atlas (Reyes 2005). Exploring the Concept of Cybercartography, Brian et al. (2005, p. 53) consider the user in a broader societal/ human context. In their model there is a synthetic cybercartographic human interface consisting of three interfaces/domains: cybercartographic or content processing 


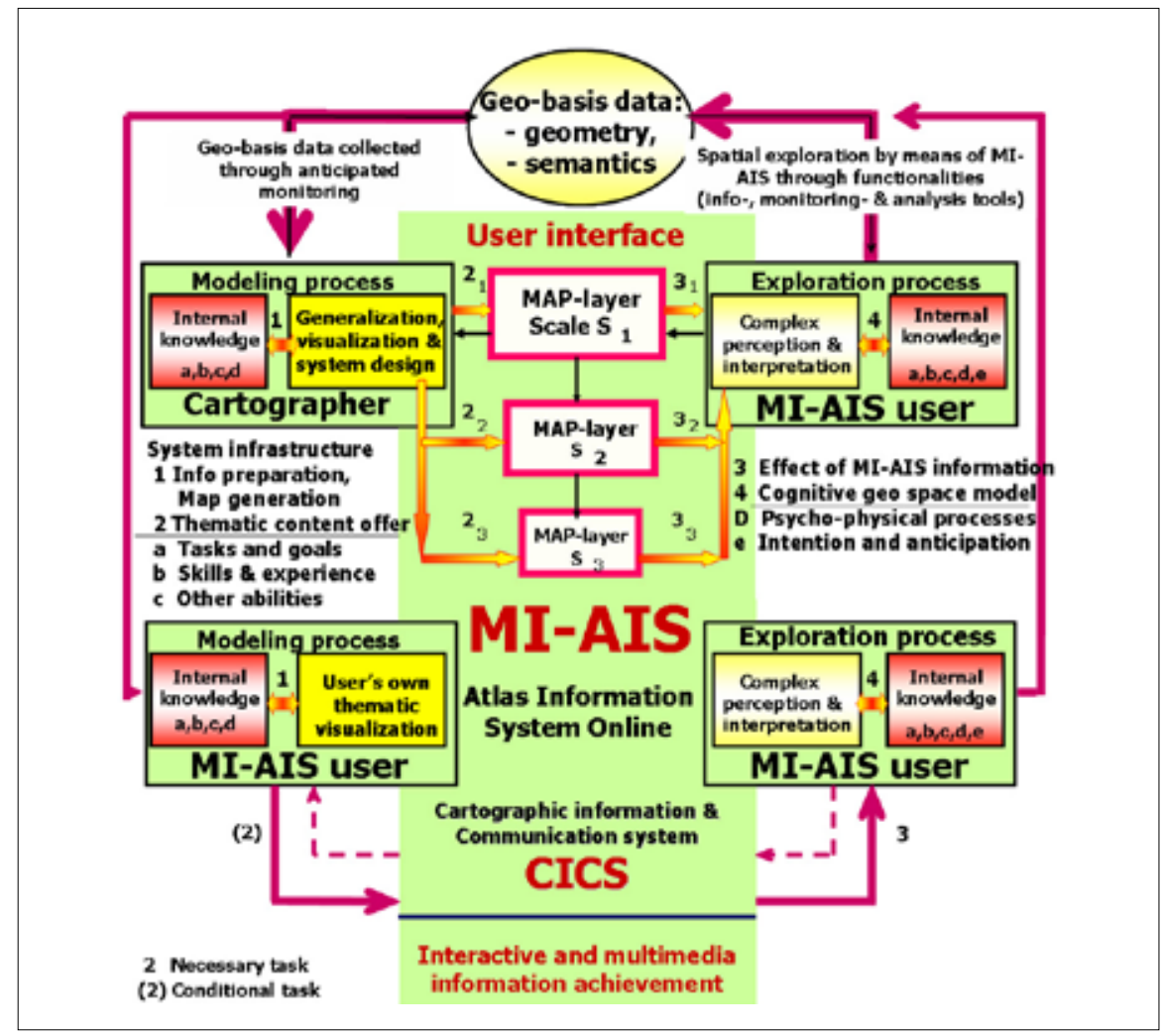

Fig. 24.1. Cartographic geo-communication process in CICS, especially in MI-AIS.

domain, human and interface domain and the complete information package, will be processed in sequential, hierarchical, and evolutionary patterns including three general levels: data (transactional processing), knowledge (analytical processing) and meaning (synthetic processing).

But back to the traditional geo-communication process in a CICS. Map generation without adequate application of cartographic knowledge and working with the restrictions of current visualisation tools for different cartographic media in CICS often do not conform to "ideal" cartographic modelling instructions and principles.

\subsection{Characteristics of Cartographic Media}

The goal of cartography is to communicate clear and legible information about geo-space objects, states and phenomena via geo-coded map-objects in various cartographic media (Figure 24.2), in which the map is most often used. 


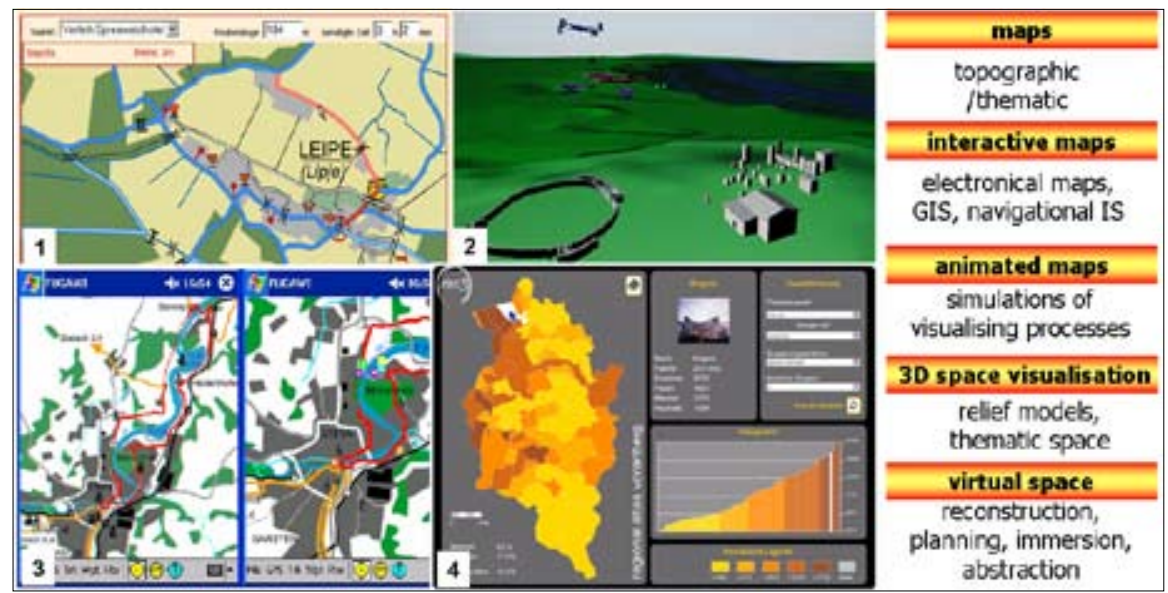

Fig. 24.2. Cartographic media involved in CICS (1: Blum 2003, 2: Jobst 2003, 3: Leitner 2003, 4: Stadler 2006)

Cartographic modelling for all cartographic media includes the complex iterative process of cartographic generalisation, visualisation and unavoidable harmonisation of graphically transformed geo-objects from the primary spatial model into map-objects of the secondary spatial model (Lechthaler 2007). Description or meaning, i.e. geo-object semantics, is tied to the map graphics, whose form and position is defined by the scale. The meaning is generalised and is related to a previously determined hierarchy (i.e. roads classified into groups). In this way, individual marks of individual geo-objects are changed, represented incompletely not sharp enough or disappear completely. For cartographic models, in order to be legible and understandable for the user, the map graphics have to be adjusted to the user's perceptive parameters a as well as to technical restrictions of the publishing media: paper or display. These are immanent characteristics of the cartographic model as an efficient geo-communication tool and have to be applied unconditionally in all cartographic media.

\subsection{Characteristics of Atlas Information Systems}

As defined in the Lexicon of Cartography and Geomatics (Bollmann et al. 2002), an atlas map work is understood as a target and purpose oriented systematic set of maps in book form or as an AIS with global, regional and local character, which offers static and dynamic maps (2.5D and 3D), texts, tables, pictures and graphics as well as computer-aided sequences like language, sound, animations and videos.

Abraham Oertel, named Ortelius (1527-1598), published his "Theatrum Orbis Terrarum" as the first map collection satisfying the atlas definition, and in 1585, 
Gerhard Kremer, called Mercator (1512-1594) was the first to give his map collection „Atlas sive Cosmographicae Mediationes de Fabrica Mundi et Fabricati Figura” the name "Atlas" (Lechthaler 2009).

In accordance to formal and relevant features, Bollmann et al. (2002) distinguish among atlases with regard to:

- output medium/presentation form (paper, haptic, electronic, multi-media atlas),

- thematic contents (complex thematic atlas, special atlas),

- format and content size (giant-, hand-, book- and pocket atlas),

- representation area (world-, countries-, regional-, town-, space-, moon atlas).

Beside these traditional classifications of atlases, digital atlases are classified more specifically. Considering the level of interactivity and the analytic potential, Ramos et al. (2005) and Ormeling (1996) categorise digital atlases as:

- view-only atlases (print-only atlases or digital static maps without interactivity or dynamics),

- atlases that generate maps on demand (interaction with data sets, changes of colour schemas, classification methods or number of classes), and

- analytical atlases based on GIS capabilities (database queries through a map as a graphical interface, in addition to provided map possibilities to create, analyse and visualise new data sets).

An AIS is primarily used to locate geographic phenomena and to enable users to understand geo-spatial patterns related to the physical, temporal or socio-economic human environment. Atlases belong to the first cartographic products that people use, as they are introduced to students early in their education. Further, atlases can be considered as the most widely known and ultimate cartographic product (Kraak 2001) and play an important role in cartographic geo-communication.

A national atlas is the cartographical calling card of a country (Hurni 2004). Unlike topographical maps of a country, national atlases additionally convey thematic information based on a consistent succession of map scales. A number of electronic national AIS have been produced within the last twenty years. Due to the new potential of the global net, national atlases become more and more important in society. Ormeling (2001) defines the concepts for multimedia national AIS and points out the new meaning of the Web atlas map as an interactive interface, which provides access to the current elementary geo-data portal (sub national, national, translational and global data bases). Naturally, there are still many unanswered questions, especially regarding national geo-data policy.

As an example of European national MI-AIS, the following atlases have to be mentioned (this list is not exhaustive): National Atlas of the Federal Republic of Germany, Atlas of Switzerland, Online Atlas of the Netherlands, Online Atlas of Canada, GeoInfo Austria and ÖROK Atlas Online - AIS Austria. 


\subsection{Paper Atlases Versus Web AIS in the Cartographic Geo-Communication Process}

Analogous maps in an atlas are dual-purpose. On one hand they must store information, and on the other hand they communicate information about geo-objects and -phenomena. The extent of spatial semantics related to qualitative and quantitative characteristics should be harmonically organised as well as constructed on a piece of paper. Markers and various kinds of stickers are employed by atlas users in order to find or compare map contents and define relevant objectives. Atlas maps are accompanied by explanatory booklets, containing notes, profiles, statistics, diagrams, pictures, etc.

AIS dates from the eighties of the last century and was characterised by hardware limitations (storage capacity) as well as software limitations (lack of interactive tools). The first developed digital atlas was the Electronic Atlas of Canada in 1981. Since then, increasing research efforts have been carried out in this field by governments, universities and private companies (Kraak et al. 2003, Peterson 2005).

Some of the important differences between paper atlas and contemporary digital AIS are the kind of atlas storage and the publishing of geo-space information. The expressive growth of the Internet audience (Peterson 2005) allows distributing the atlas content via wire/wireless network ubiquities to countless people. This is also a very effective way of distributing the meaning of cartography.

In modern cartography, the Web offers an ideal platform for enhancing geo-communication by means of map information. But at the same time, it is necessary to understand the process and the methods of how to generate cartographic models and how to accurately and efficiently communicate spatial data and information. Due to this focus, cartography is obliged to achieve both - the creation of cartographic media and the acceptance of being responsible to understand the deep relationships between the whole CICS, which includes the user, the models and the data transmission.

Furthermore, this article is focused on cartographic visualisation in the MI-AIS cartographic media.

\subsection{Cartographic Visualisation in the MI-AIS Cartographic Media}

Cartography is exposed to constant changes in the technical environment. The largest technical revolution of the 20th century was the transition from static paper-printed maps to interactive display visualisations in MI-AIS. This transition was probably the most significant innovation in the history of cartography (Hurni 2005, 2006). 
Computer-aided cartographic modelling and processing, and the representation of map-objects in vector space heavily influenced the rapid development of MI-AIS. The use of innovative functions and tools in technological systems, e.g. geographic information systems (GIS), computer-aided modelling (CAD), desktop-publishing, raster graphics processing, Web geo-communication, as well as the development of various program languages actually are the catalysts in the development of digital and interactive cartography.

Today, the choice of interactive CICS has become immense and is very wide in technological and thematical terms (Hurni 2006). From the cartographic perspective, the mentioned systems attribute completely different importance to the principles of cartographic modelling, where the cartographer's experience and knowledge often takes the back seat.

Using legible map graphics that are adapted to the technical requirements of the output medium (Lechthaler et al. 2007a) is one of the main criteria for user acceptance of MI-AIS. Concerning the definition of cartographic legibility regarding the printed maps, much experience has been gained within the last few decades.

The situation is not the same for screen visualisation. Electronic atlases have not yet reached a high level, especially concerning the legibility of the represented geo-information (Prohaska 2005), although the increased demand for interoperability and flexible exchange of formats is impelling a greater standardisation of geo-data. The "standard" discourse of recent decades has largely ignored graphic quality and visual effectiveness (Monmonier 2005). Due to their technical restrictions, screen presentations suffer from deformation of the graphic elements that limit the legibility of the map.

Therefore, the adaptation of these map graphics is essential. This could be achieved by (Lechthaler et al. 2007b):

- defining minimal dimensions (size and distance) of map graphics and lettering which is dependent on direction and shape,

- careful choice of the basic elements for graphic representations (points, lines, polygons, complex map signs and characters), and

- deliberate choice and combination of graphic variables (size, shape, colour, orientation, lightness, and patterns).

The application of screen-adapted map graphics requires more map-space. This has an effect on the information content of the atlas map in terms of insufficient information transfer due to larger map graphics. However, lower graphic density is compensated by the ability to fully investigate the range of content with implemented interactive facilities to access primary geo-data. This leads to a more efficient system with hardly any capacity limits. 


\subsection{Some Interactive and Multimedia Cartographic Applications in CICS}

The general borders that define cartographic communication are changing. Cartographic presentations, which no more only remain static but become dynamic, - interactive and animated - whenever possible, have become a new input/output user-controlled interface. The cartographer is no longer constrained to create a single map for a single user or well-known user group. In the cartographic communication process the user has more possibilities to go beyond the limitations of static maps through new technologies which are linked to presented map information. Such information systems using cartographic models as a user's interface for gathering selective and targeted geo-information are associated with unlimited information capacity on the one side, and, on the other, they demand changed habits due to the readout the system offers.

\section{Prototype of Interactive and Multimedia Atlas of Austria "Geo Info Austria $^{\odot 1 "}$ (Figures 24.3 and 24.4)}

The MI-AIS consists of several scales, i.e. inherent information levels (geometry and object-semantics) (Kelnhofer 2000). The topographically and thematically defined interactions, animations and multimedia sequences guide the user on his way to information acquisition through Austrian space by using the maps as interactive interfaces. User defined queries in topographic and/or thematic domains can be analysed or visualised by cartographic means. The legibility and quality of cartographic information is of permanent importance.

\section{Prototype of the PC school atlas InMuCIS ,Interactive Multimedia Cartographic Information System about geo-phenomena ${ }^{\odot \text { " Brunner- }}$ Friedrich (2004) (Figure 24.5)}

Brunner-Friedrich (2004) presents the concept of a school atlas and postulates that users of MI-AIS show different abilities and preferences within their scientific information perception.

Each individual student needs a different approach to the learning matter (in this case cartographic topics) and a different kind of presentation to improve his memorisational skills. Students exhibit different learning styles and can therefore be classified in different types of learners. Today's teaching aids often address only some or just one of those learning types, whereas others are left completely unattended.

${ }^{1}$ AIS GeoInfo Austria is the result of a FWF project (1995-2000), developed at the Department of Cartography and Geomedia Technique (today Department of Geoinformation and Cartography, Research group Cartography), University of Technology, Vienna (Kelnhofer 2000). 


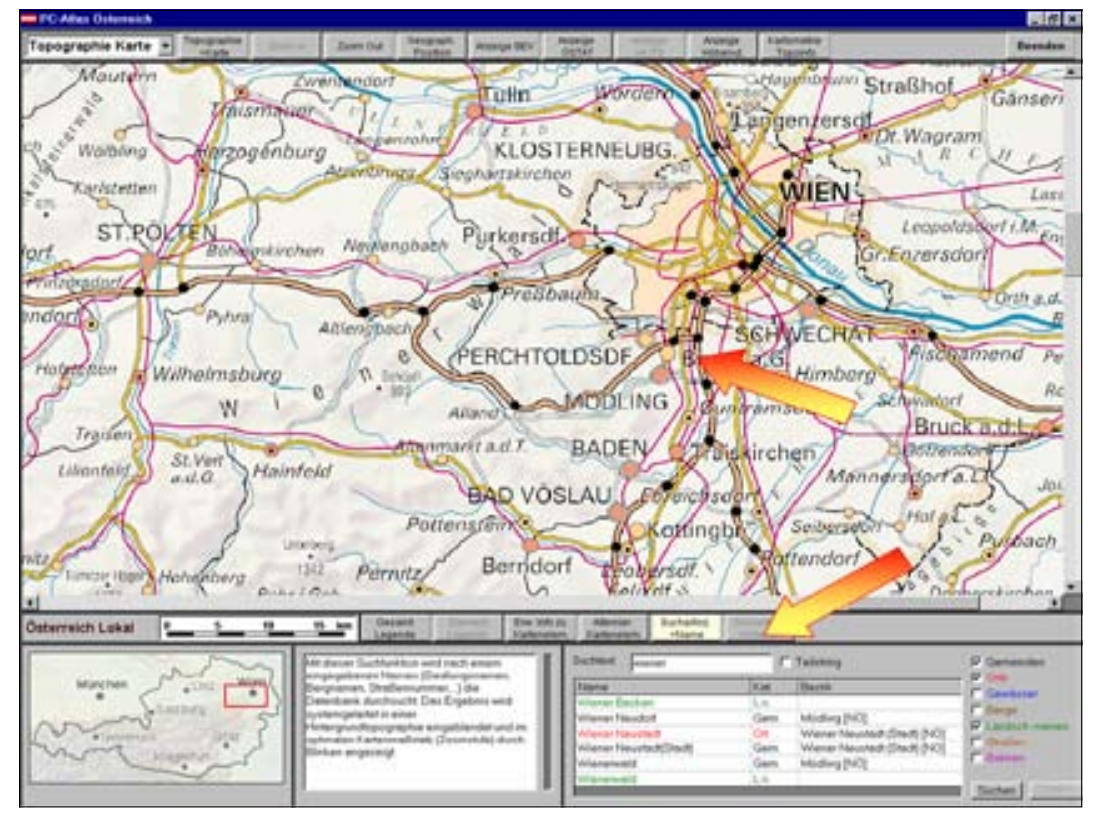

Fig. 24.3. Example of user's information acquisition by queries and interaction within the topographical map-space in "Geo Info Austria $\complement$ ".

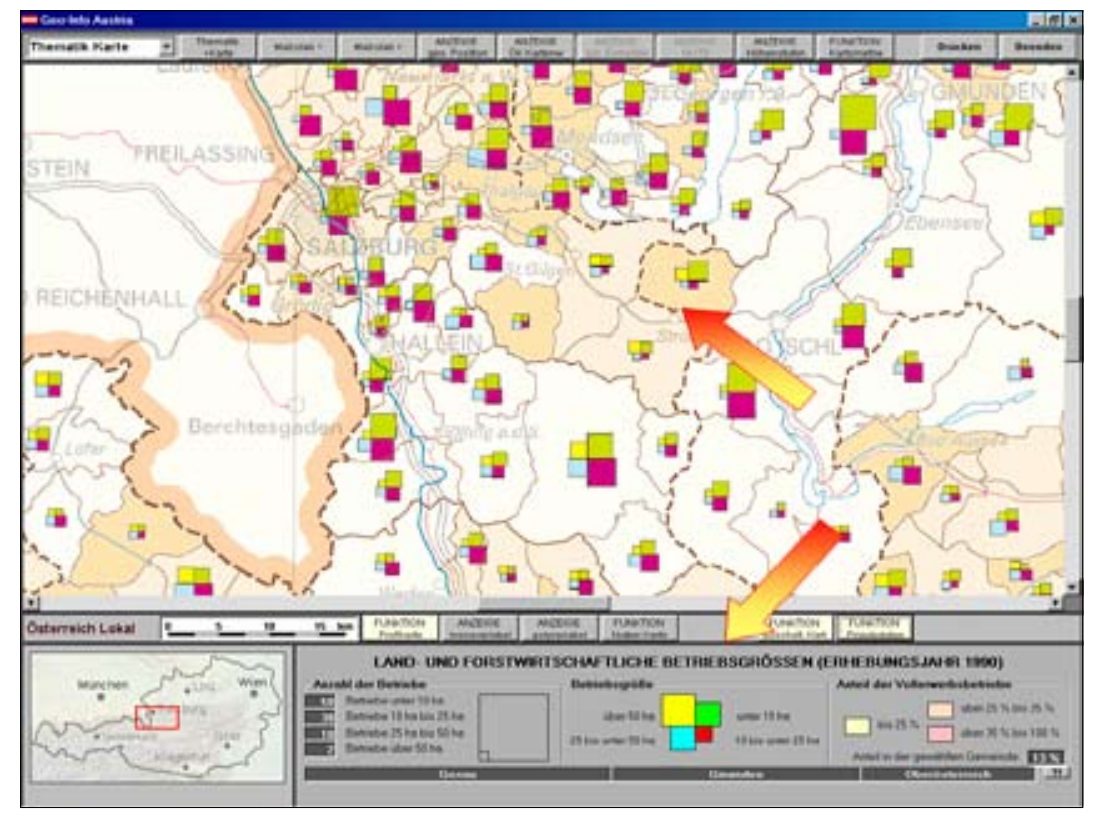

Fig. 24.4. Example of user's information acquisition by queries and interaction within the thematical map-space in "Geo Info Austria(C)" 


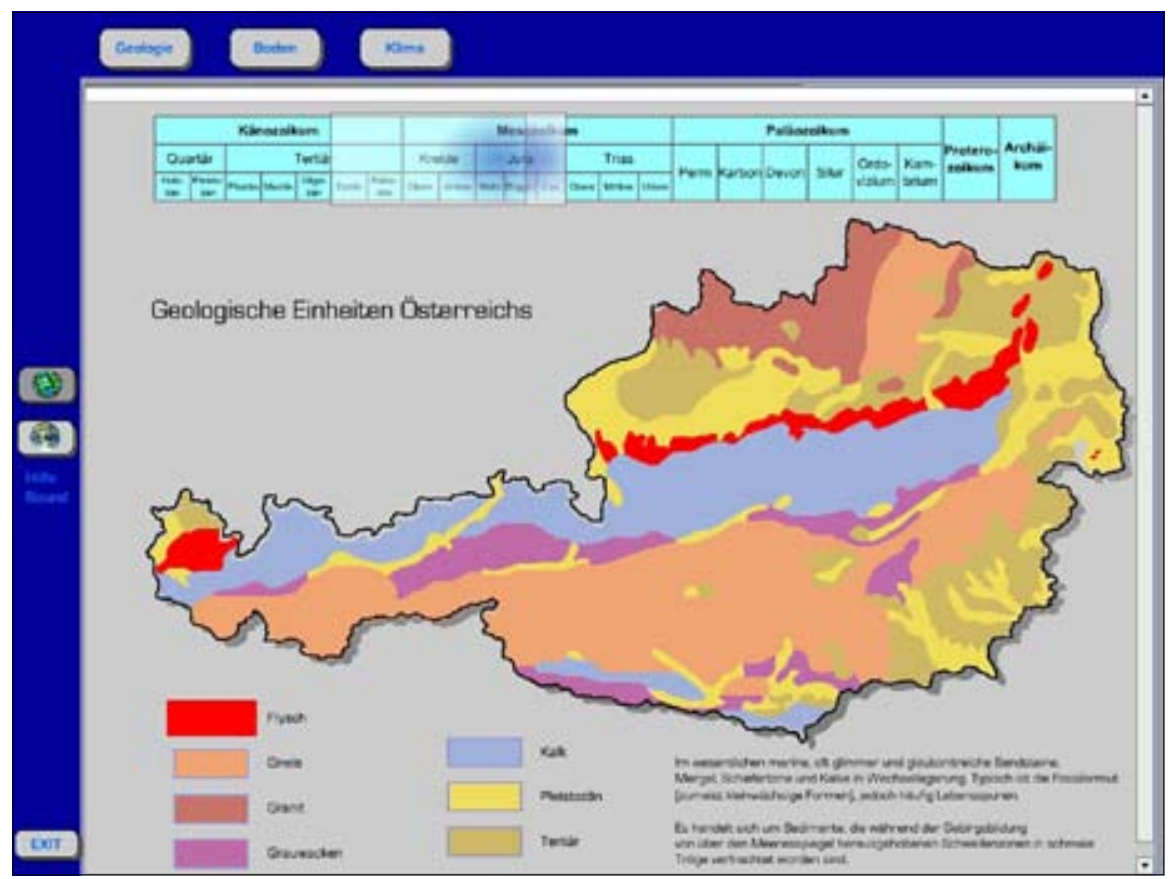

Fig. 24.5. Example of user's information acquisition by queries and interaction within the thematical map-space in Prototype of the PC multimedia school atlas InMuKIS „, Interactive Multimedia Cartographic Information System” Brunner-Friedrich (2004).

To consider these differences it seems necessary to offer the same (spatial) information in various ways, i.e. no change in the information content but in the type of presentation. This could be done by applying some new technologies on spatial data which are delimited in a fuzzy manner in this CICS. To avoid overlays in maps a new display concept is used. A new display concept is used, which incorporates user strategies (such as individual knowledge or learning habits) based on findings in cognition psychology.

Independent exploration is supported by the use of different media (interactive maps/“view-only" maps; maps with/without acoustic elements; written/spoken text), different cartographic presentation forms (e.g. map/aerial view), and different cartographic symbols (from geometric-abstract to pictorial).

\section{ÖROK Atlas Online - AlS Austria}

"ÖROK Atlas Online - AIS Austria" is an interactive and multimedia rule based thematic atlas provided by the Austrian Conference on Spatial Planning (ÖROK) (Figures 24.6 and 24.7), which is an organisation set up by federal, regional and local governmental administrations of Austria to coordinate spatial planning at the 


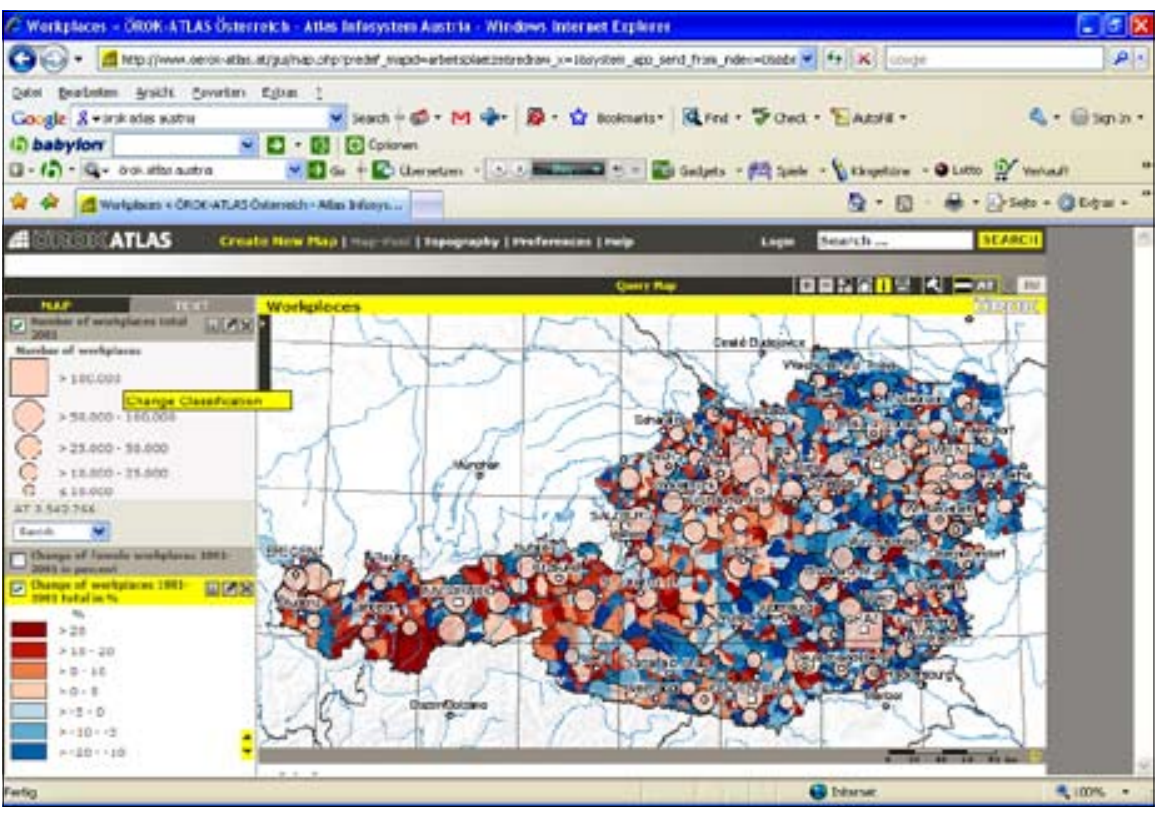

Fig. 24.6. Example of user's information acquisition by queries and interaction within the thematical map-space - Workplaces 2001 - in ÖROK Atlas Online (www.oerok-atlas.at).

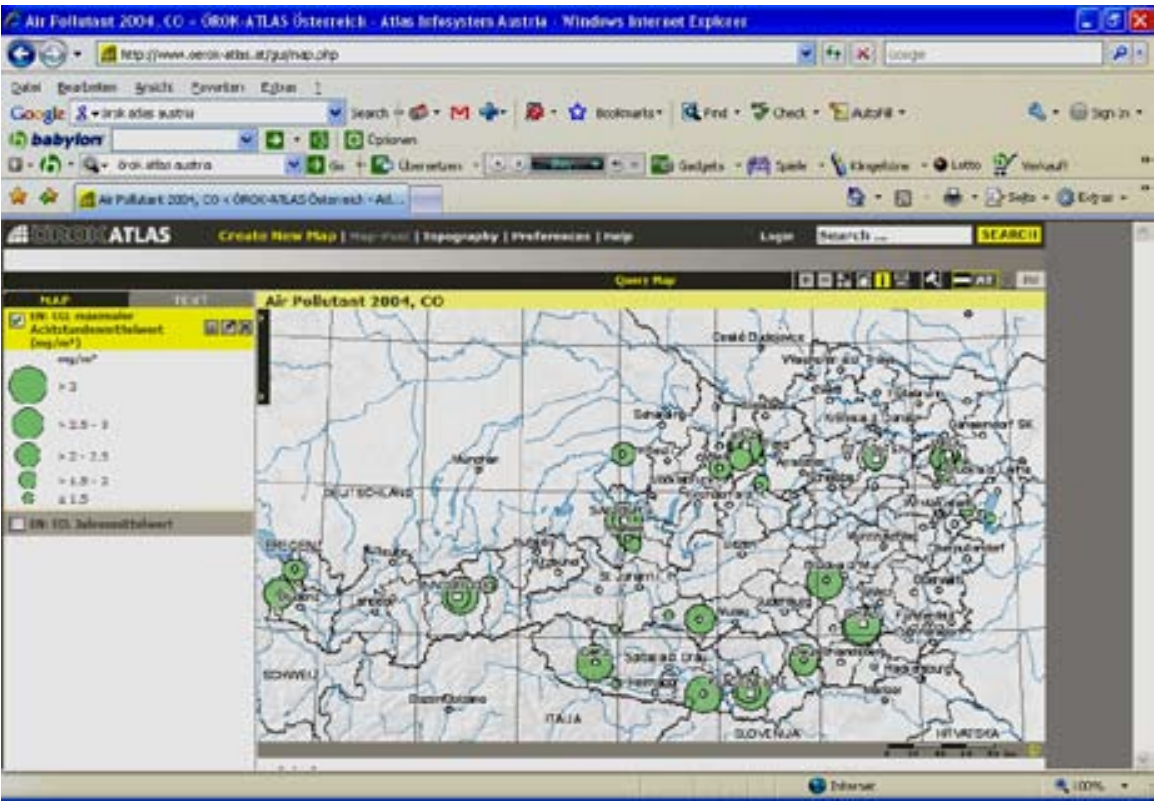

Fig. 24.7. Example of user's information acquisition by queries and interaction within the thematical map-space - Air Pollutant 2004 - in ÖROK Atlas Online (www.oerok-atlas.at). 
national level. The atlas application is the result of a cooperative research and development project of the ÖROK, Department of Geoinformation und Cartography, University of Technology, Vienna/Austria ${ }^{2}$, Department of Geography and Regional Sciences, University of Vienna ${ }^{3}$ and ÖIR-Information services, Vienna ${ }^{4}$. (Prototype's timetable was: September 2004 - February 2006).

This atlas is a web online system which enables the user - lay persons and experts - to explore national and international (European) basic geo-data. Users can perform tasks like searching, comparing, analysing and visualising data. The system allows the cartographical visualisation of geometry and statistical data from the elementary geo-data pool in different map scales and in a high quality. Graphics, statistics and texts as well as queries of the data base are accessible over the interactive map based graphical user interface as a communication portal (Lechthaler 2007).

The main research emphasis of the "ÖROK Atlas Online - AIS Austria" as a national MI-AIS lies in the formalisation of the cartographical rules for proper thematic online modelling and visualisation of geometry and thematic data in the given scale resolution, further in the definition and realisation of required functionalities which make efficient communication possible, and in the system navigation and applied interactions which support a sensible and meaningful "restrictiveflexible" user leadership.

In accordance to the theme choice the system navigation has to support the users in their exploration. It can be assumed that system users usually are not interested in undertaking several experiments, or in using different kinds of e.g. symbols, symbol sizes, line widths, or patterns until they have achieved an acceptable map. Therefore, a so-called system control should support the efforts of system users in the process of map making. In the system background data queries as well as meta-data and data analysis, cartographic data modelling (selection of the best method for the scaledependent and graphic-defined data translation), and cartographic visualisation are formalised. Predefined processes have been deliberated by the consortium group in order to give the user a restricted freedom. Within the restrictions defined by the system control, the user can explore the geo-space via AIS Austria in a flexible way according to his questions. In such way, only sensible, convincing and useful cartographical data presentation are permitted (Lechthaler et al. 2005b).

\footnotetext{
${ }^{2} \mathrm{http}: / /$ cartography.tuwien.ac.at

${ }^{3} \mathrm{http}: / / \mathrm{www}$. gis.univie.ac.at/karto

${ }^{4} \mathrm{http}: / /$ www.oir.at
} 


\subsection{Summary and Conclusions}

Technological developments of the last two decades have led to a wider range of different cartographic media implicated in cartographic information and communication systems (CICS). The most important and complex systems enabling the user to search for new knowledge are interactive and multimedia atlas information systems (MI-AIS), which include cartographic, linguistic, mathematical, statistical, acoustical, and visual languages. Cartographic information in thematic and/or topographic maps, virtual space maps, dynamic three-dimensional satellite images, geotexts, videos, photos, sound, computer simulations, statistical graphs, and diagrams allow to construct individual worlds of space information.

Atlas Information System (AIS) as a cartographic geo-communication platform is different from pure GIS due to its strong cartographic character. This is particularly shown by the fact that it is not merely a collection of GIS based tools, but a system which subdivides all functionalities into a cartographically coherent and structured order. It must correspond with the characteristics of the cartographical, rule-based and personalised information system, which enables different user groups to explore current elementary geo-data from different geographical and thematic sources. Hence, the formerly passive user of a map becomes an active manager in geographic information acquisition and visualisation. The role of cartographers as designers of AIS has changed, too. They are not only responsible for transport of cartographically legible screen information via the Web, but also for all applied technological functions which allow the user to communicate online with the system.

\section{Acknowledgement}

The author has worked on many maps in both MI-AIS applications: Geo Info Austria and ÖROK Atlas Online. My thanks for permission to present the results in the Figures 24.3 - 24.7. Many thanks also for the permission to use the images of diverse diploma theses in Figure 24.2.

\section{References}

Bluhm R (2003) Konzipierung eines benutzerfreundlichen kartographischen TIS am Beispiel der Region Spreewald - Wasserwanderwege. Diploma thesis, Department of Geoinformation and Cartography, Vienna University of Technology

Board C (1978) How can theories of cartographic communication be used to make maps more efficient? In: Kirschbaum GM, Meine KH (Eds) Internationales Jahrbuch für Kartographie. Kirschbaum, Bonn. 41-49 
Bocharov MK (1966) Osnovy teorii proektirovanya sistem kartograficheskikh znakov. Nedra, Moskva

Bollmann J, Koch WG (2002) Lexikon der Kartographie und Geomatik. Heidelberg, Spektrum

Brian GE, Taylor DRF (2005) Exploring the Concept of Cybercartography Using the Holonic Tenets of Integral Theory. In: Taylor DRF (Ed) Cybercartography: Theory and Practice. Elsevier, Amsterdam. 63-99

Brunner-Friedrich B (2004) Entwicklung eines Konzeptes für ein benutzerabgestimmtes multimediales Interaktives Informationssystem über Geophänomene - vorgestellt anhand eines exemplarisch ausgefertigten digitalen Schulatlasses für die 11. Schulstufe. PhD-thesis. Vienna University of Technology

Cartwright W, Peterson MP (1999) Multimedia Cartography. In: Cartwright W, Peterson MP, Gartner G (Eds) Multimedia Cartography. Springer, Berlin. 1-10

Goodchild MF (2000) Cartographic Futures on a Digital Earth. In: Cartographic Perspectives, 36:3-11

Grygorenko W (1984) A cybernetic model of cartographic communication. In: Kirschbaum GM, Meine KH (Eds) Internationales Jahrbuch für Kartographie. Kirschbaum, Bonn. 95-107

Hurni L (2004) Vom analogen zum interaktiven Schulatlas: Geschichte, Konzepte, Umsetzungen. In: Kainz W, Kriz K, Riedl A (Eds) Aspekte der Kartographie im Wandel der Zeit. Institut für Geographie und Regionalforschung der Universität Wien. 222-233

Hurni L (2005) Anwendung kartographischer Medien im Rahmen aktueller I+K-Technologien. $\mathrm{KN}, 5: 244-249$

Hurni L (2006) Interaktive Informationssysteme - Quo vaditis? KN, 3:137-142

Jobst M (2003) Der Einsatz multimedialer Technologien in kartenverwandten Darstellungen am Beispiel Carnuntum. Diploma thesis, Department of Geoinformation and Cartography, Vienna University of Technology

KelnhoferF(2000)DasdualePrinzipinderAtlaskartographie,ErgebnissedesFWF-Teilprojektes „Geoinformationssysteme und EDV-Kartographie“. In: Seger M (Ed) Mitteilungen der Österreichischen Geographischen Gesellschaft, Wien, ÖGG, 142:38-68

Knöpfli R (1980) Informationstheoretische Betrachtungen zur Verringerung von Ungewissheit durch Struktur. In: Kirschbaum GM, Meine KH (Eds) Internationales Jahrbuch für Kartographie. Kirschbaum, Bonn. 118-129

Kolačny A (1970) Kartographische Informationen - ein Grundbegriff und Grundterminus der modernen Kartographie. In: Kirschbaum GM, Meine KH (Eds) Internationales Jahrbuch für Kartographie. Kirschbaum, Bonn. 186-193

Kraak MJ (2001) Web Maps and Atlases. In: Kraak MJ, Brown A (Eds): Web Cartography, Taylor and Francis, London. 135-140

Kraak MJ, Ormeling FJ (1996) Cartography: visualization of geospatial data. Longman, Essex

Kraak MJ, Ormeling FJ (2003) Cartography, visualization of spatial data. 2nd Edition. Pearson Education, Harlow

Leitner M (2003) Konzeption eines Informationssystems für Radtouristen für verschiedene Ausgabemedien. Diploma thesis, Department of Geoinformation and Cartography, Vienna University of Technology

Lechthaler M (1985) Entropie der Geländedarstellung durch Höhenlinien an einer Reihe topographischer Karten. Nostrifizierte Dissertation an der Technischen Universität Wien. 
Lechthaler M (2000) Map-space as user interface in the interactive and multimedia cartographic system. In: Kereković D (Ed) Proceedings of International conference - GIS Croatia. Zagreb: GIS Forum, Croatia. 20-26

Lechthaler M (2002) Concept of map based city guide - using mobile internet for location based services. In: Kereković D (Ed) Proceedings of International Conference GIS Odyssey 2002. Split/Croatia. GIS Forum, Zagreb/Croatia. 13-23

Lechthaler M (2003) Neue Herausforderungen an die Kartensemiotik? Vom Georaum zum Karten(raum) und zurück. In: WolodtschenkoA, Schlichtmann H(Eds) Diskussionsbeiträge zur Kartensemiotik und zur Theorie der Kartographie. Internationales KorrespondenzSeminar. Dresden, Technische Universität Dresden. 11-27

Lechthaler M (2005a) Bildschirmgerechte kartographische Visualisierung der Geobasisdaten in digitalen Atlas-Informationssystemen. In: Strobl J, Blaschke T, Griesebner G (Eds) Angewandte Geoinformatik 2005, Beiträge zum 17. Agit-Symposium Salzburg, Herbert Wichmann Verlag, Heidelberg. 403-412

Lechthaler M, Spanring C, Katzlberger G (2005b) Cartographic Concept of Atlas Information System „ÖROK Atlas Online“ - AIS Austria. In: Lapaine M (Ed) Kartografija i Geoinformacije. Journal of the Croatian Cartography Society. 4:30-45

Lechthaler M (2007) Hybrid System Design for Cross-Media Publishing in the national Atlas Information System. Proceedings of XXII International Cartographic Conference: Cartography for everyone and for you, Moscow, DVD medium

Lechthaler M (2009) The World Image in Maps - from the Old Ages to Mercator. In: Cartwright W, Gartner G, Lehn A (Eds) Cartography and Art,Springer, Berlin

Lechthaler M, Stadler A (2007a) The meaning of cartographic spatial data geovisualization in a multimedia interactive atlas information system; Kartografija i Geoinformacije, Zeitschrift der Kroatischen Kartographischen Gesellschaft, Zagreb. 1, 7:4-18

Lechthaler M, Stadler A (2007b) „Cross media“ gerechte Kartengraphik in einem AIS. In: Schrenk M (Ed) Proceedings of 11th International Conference CORP 2007, Competence Centre for Urban and Regional Development, Wien

MacEachren AM (1994) Visualization in modern cartography: setting the agenda. In: MacEachren AM, Taylor DR (Eds) Visualization in modern cartography. Pergamon Press, London. 1-13

MacEachren AM (1995) How maps work; representation, visualization and design. Guilford, London

Monmonier M (2005) Pomp and circumstance: Plain Old Map Products in a Cybercartographic World. In: Taylor DRF (Ed) Cybercartography, Elsevier, Amsterdam. 15-35

Morisson JL (1976) The science of cartography and its essential processes. In: Kirschbaum GM, Meine KH (Eds) Internationales Jahrbuch für Kartographie. Kirschbaum, Bonn. 85-97

Ormeling F (1996) Functionality of Electronic School Atlases. In: Köbben B, Ormeling F, Trainor T (Eds) Seminar on Electronic Atlases II, ICA Proceedings on National and Regional Atlases. Prague. 33-39

Ormeling F (2001) Das Bändigen von Multimedia-Konzepten für den Online-Atlas der Niederlande. In: Herrmann C, Asche H (Eds) Web.Mapping 1 - Raumbezogene Information und Kommunikation im Internet, Wichmann, Heidelberg. 178-189

Peterson MP (1995) Interactive and animated cartography. Prentice-Hall, London

Peterson MP (2005) Hypermedia Maps and the Internet. In: Stefanikis E, Peterson MP, Armecanis C, Delis V (Eds) Geo-Hypermedia'05, Proceedings of the 1. International Workshop on Geographic Hypermedia, Denver, Colorado, USA 
Prohaska S (2005) Interaktive Visualisierung und Datenanalyse: Herausforderung durch wachsenden Datenmengen. In: Dodt J, Rase WD (Eds) Aktuelle Entwicklungen in Geoinformation und Visualisierung. Kirschbaum, Bonn. 10:103-111

Ramos CS, Cartwright W (2005) Atlases from paper to digital medium. In: Stefanikis E, Peterson MP, Armecanis C, Delis V (Eds) Geo-Hypermedia'05, Proceedings of the 1. International Workshop on Geographic Hypermedia, Denver, Colorado, USA

Ratajski L (1978) The main Characteristics of Cartographic Communication. In: Kirschbaum GM, Meine KH (Eds) Internationales Jahrbuch für Kartographie. Kirschbaum, Bonn. 21-32

Reyes M (2005) Cybercartography from a Modelling Perspective. In: Taylor DRF (Ed) Cybercartography: Theory and Practice. Elsevier, Amsterdam. 63-99

Stadler A (2006) Interaktives AtlasInformationSystem rav3 (RegionalAtlas Vorarlberg). Course:EDV-Modul 10-Informa-tionstechnologie undEDV-gestütztePlanungsmethoden. Department of Geoinformation and Cartography, Vienna University of Technology

Sukhov VJ (1967) Information capacity of entropy. Geodesija i aerofotosemka. 4:212-215

Taylor DRF (1994) Perspectives on Visualization and Modern Cartography. In: MacEachren AM, Taylor DRF (Eds) Visualization in modern cartography. Pergamon Press, London. 333-341 